\title{
EDITORIAL
}

\section{Emergency treatments in pulmonary arterial hypertension: a place for algorithms and for education programmes}

\author{
B. Degano
}

$\mathbf{P}$ ulmonary arterial hypertension (PAH) is a rare and severe condition characterised by vascular proliferation and remodelling of the small pulmonary arteries, resulting in a progressive increase in pulmonary vascular resistance leading to right ventricular failure and premature death [1]. Two decades ago, patients with idiopathic PAH had a dismal median survival rate from diagnosis of $<3 \mathrm{yrs}$, despite available supportive treatment [2]. Since then, meaningful randomised controlled trials have been conducted thanks to a worldwide collaboration of expert centres operating with a similar standard of medical care [3, 4]. Eight drugs belonging to three pharmacological classes (endothelin receptor antagonists, phosphodiesterase type-5 inhibitors and prostanoids) administered by four different routes (oral, inhaled, subcutaneous and intravenous) have been approved [5]. None of these therapies is curative, but they contributed to allow PAH to evolve from a uniformly fatal condition to a chronic disease in some cases [6].

Because of the rarity of PAH and the need for specific management of this disease, many countries have chosen a pyramidal organisation of patient management. Such organisation comprises one (or few) reference centres, several competence centres (located mostly in university hospitals), local specialists and general practitioners. On one side, reference centres and many competence centres offer specific expertise on $\mathrm{PAH}$, an adapted technical platform, a multidisciplinary team working in a shared care approach and research expertise [7]. On the other side, local specialists and general practitioners are most often those who have detected the first symptoms of the disease and/or who have diagnosed pulmonary hypertension, and also those who will manage some of the medical problems occurring during the course of the disease. However, as PAH is a rare disease, it is likely that local specialists and general practitioners will only rarely be confronted with some medical complications of PAH. Moreover, these medical complications most often need a rapid decision together with a specific management, and guidelines for the emergency treatments for PAH are currently

CORRESPONDENCE: B. Degano, Dept of Physiology and EA 3920, CHU de Besançon, Bd Fleming, 25030 Besançon Cedex, France. E-mail: bruno.degano@univ-fcomte.fr

Received: June 28 2010; Accepted: June 302010

PROVENANCE: Submitted article, peer reviewed. missing. It is of great merit that DeLCROIX and NAEIJE [8], in the current issue of the European Respiratory Review give indications to doctors unaware of acute medical problems in $\mathrm{PAH}$. The authors have revisited their database and then have examined the management of the most prevalent of these potentially life-threatening problems $[9,10]$. The sole question of the management of a cardiac arrest highlights the difficulties of the real life management $[1,11]$. On one hand, a doctor confronted with an imminent cardiac arrest must know that a patient with advanced $\mathrm{PAH}$ should not necessarily be resuscitated [12]. On the other hand, he has to know where to find an algorithm that will guide his decision and, also, where to find the medical information concerning the patient, in order to decide what to do.

As highlighted by Delcroix and NAeIje [8], all the indications for emergency treatments will be better used if a pyramidal (or "transmural") medical organisation is achieved. In this organisation, the question arises as to whom to educate first, the patients or the general practitioners. One possible answer is that reference and/or competence centres should first deliver educational programmes to their patients. The central idea is that each patient (and, in some cases, their relatives) must have information on their illness and on PAH that will help doctors to find the right information at the right time. Indeed, it is almost impossible to deliver educational programmes for all rare diseases to all general practitioners, especially in a context where knowledge is evolving rapidly. Nevertheless, professionals need to have real-time access to validated and updated recommendations for clinical practice. The availability of validated information that is pertinent and easy to access, is essential to improve patient care. From a practical point of view, each patient should have an accessible and easily understandable document, in which one will find updated medical information, medical history, and last main clinical and biological data, for example. In such a document, professionals should also easily find a website address or a telephone number where the needed information is available in their own language. Reference and/or competence centres should prepare the document and verify that it is regularly updated.

In $\mathrm{PAH}$, some difficult decisions must be rapidly taken. It is also to the merit of the paper by Delcroix and NAeIje [8] to provide some striking messages through clinical cases. One of 
these messages is "not to underestimate the risks". It means that a doctor must recognise a situation at risk, and then decide what to do with the help of a reference/competence centre. Another message is that "elective surgery should be performed at a PAH centre under the supervision of an experienced cardio-anaesthesiologist with access to all PAH therapies". Again, there must be a link between professionals who are unaware of the specificities of PAH and reference/ competence centres, and this link should be "education".

\section{STATEMENT OF INTEREST}

None declared.

\section{REFERENCES}

1 Galie N, Hoeper MM, Humbert M, et al. Guidelines for the diagnosis and treatment of pulmonary hypertension. Eur Respir J 2009; 34: 1219-1263.

2 Naeije R. Treatment of right heart failure on pulmonary arterial hypertension: is going left a step in the right direction? Eur Respir Rev 2010; 19: 4-6.

3 Humbert M, Sitbon O, Chaouat A, et al. Survival in patients with idiopathic, familial, and anorexigen-associated pulmonary arterial hypertension in the modern management era. Circulation 2010; 122: 156-163.

4 Humbert M, Sitbon O, Yaici A, et al. Survival in incident and prevalent cohorts of patients with pulmonary arterial hypertension. Eur Respir J 2010; [Epub ahead of print DOI: 10.1183/09031936.00057010].

5 Galie N, Palazzini M, Manes A. Pulmonary arterial hypertension: from the kingdom of the near-dead to multiple clinical trial metaanalyses. Eur Heart J 2010; [Epub ahead of print DOI: 10.1093/ eurheart/ehq152].

6 Souza R, Jardim C. Trends in pulmonary arterial hypertension. Eur Respir Rev 2009; 18: 7-12.

7 Humbert M, Sitbon O, Chaouat A, et al. Pulmonary arterial hypertension in France: results from a national registry. Am J Respir Crit Care Med 2006; 173: 1023-1030.

8 Delcroix M, Naeije R. Optimising the management of pulmonary arterial hypertension patients: emergency treatments. Eur Respir Rev 2010; 19: 204-211.

9 Sztrymf B, Souza R, Bertoletti L, et al. Prognostic factors of acute heart failure in patients with pulmonary arterial hypertension. Eur Respir J 2010; 35: 1286-1293.

10 Price LC, Montani D, Jais X, et al. Noncardiothoracic nonobstetric surgery in mild-to-moderate pulmonary hypertension. Eur Respir J 2010; 35: 1294-1302.

11 Galie N, Hoeper MM, Humbert M, et al. Guidelines for the diagnosis and treatment of pulmonary hypertension: The Task Force for the Diagnosis and Treatment of Pulmonary Hypertension of the European Society of Cardiology (ESC) and the European Respiratory Society (ERS), endorsed by the International Society of Heart and Lung Transplantation (ISHLT). Eur Heart J 2009; 30: 2493-2537.

12 Hoeper MM, Galie N, Murali S, et al. Outcome after cardiopulmonary resuscitation in patients with pulmonary arterial hypertension. Am J Respir Crit Care Med 2002; 165: 341-344. 